\title{
ANALISIS POLA DAN DAMPAK SERANGAN CRYPTOJACKING DENGAN MENGGUNAKAN PENDEKATAN DYNAMIC ANALYSIS
}

Page | 39

\author{
Nur Widiyasono ${ }^{1}$, Aldy Putra Aldya ${ }^{2}$, Rifan Renanda Ardhian ${ }^{3}$ \\ ${ }^{123}$ Jurusan Informatika, Fakultas Teknik Universitas Siliwangi Tasikmalaya \\ Jl. Siliwangi No. 24, Tasikmalaya - Jawa Barat \\ Inur.widiyasono@unsil.ac.id, ${ }^{2}$ aldy@unsil.ac.id, ${ }^{3}$ rifanardhian1@gmail.com
}

\begin{abstract}
Abstrak- "Miners" bekerja untuk memecahkan masalah matematika yang kompleks untuk menghasilkan pendapatan dalam bentuk mata uang digital, seperti Bitcoin, Ethereum, Monero, dan lainnya. Proses mining ini membutuhkan perangkat keras yang serius dan sumber daya CPU yang signifikan untuk menciptakan cryptocurrency. Cryptojacking salah satu alat penambangan mata uang digital secara illegal. Cryptojacking dapat memberikan return yang lebih substansial bagi penyerang. Cryptominer jenis ini tidak terlalu membahayakan secara langsung kepada para korbannya, tetapi hanya saja menggunakan akses ilegal ke komputer korban dan menggunakan sumber daya korban untuk menambang crypto. Metode yang digunakan adalah dynamic analysis. Dinamic Analysis adalah mencari informasi atau sampel mengenai malware dengan cara menjalankannya. Dengan metode ini dapat terlihat "perilaku" dari malware tersebut sehingga selanjutnya dapat dianalisa dampak yang terjadi. Pengujian malware ini dilakukan dengan 2 cara yaitu pengujian pertama dilakukan dengan javascript injection pada jaringan lokal yang sama dengan korban yaitu wifi publik dan pengujian kedua dengan mengakses website yang terindikasi skrip cryptojacking. Berdasarkan hasil analisis menggunakan dynamic analysis dimana cryptojacking dapat menginfeksi langsung ke website atau melalui jaringan local dengan javascript injection, jika website telah terinfeksi cryptojacking maka pengunjung dari website tersebut akan menjadi korban dan terjadi penambangan tersembunyi yang akan memakan sumber daya korban dan cryptojacking operator dalang dibalik website yang terinfeksi akan menerima keuntungan dalam bentuk mata uang digital dari hasil cryptojacking ini.
\end{abstract}

Kata kunci - Cryptojacking, Injection, Malware, Mining, Website.

Abstract- "Miners" work to solve complex mathematical problems to generate income in the form of digital currencies, such as Bitcoin, Ethereum, Monero, and others. This mining process requires serious hardware and significant CPU resources to create cryptocurrency. Cryptojacking is an illegal digital currency mining tool. Cryptojacking can provide a more substantial return for the attacker. This type of cryptominer is not too dangerous directly to the victims, but only uses illegal access to the victim's computer and uses victim's resources to mine crypto. The method used is dynamic analysis. Dynamic Analysis is finding information or samples about malware by running it. With this method the "behavior" of the malware can be seen so that the impact can then be analyzed. This malware testing is done in 2 ways namely the first test is done by javascript injection on the same local network as the victim namely public wifi and the second test by accessing the website indicated by cryptojacking. Based on the results of the analysis using dynamic analysis where cryptojacking can infect directly to the website or via a local network with javascript injection, if the website has been infected with cryptojacking, visitors from the website will become victims and there is hidden mining that will eat the victim's resources and cryptojacking the mastermind operator behind the website the infected will receive profits in the form of digital currency from this cryptojacking.

Keywords - Cryptojacking, Injection, Malware, Mining, Website.

\section{PENDAHULUAN}

Kemajuan teknologi tidak hanya terlihat dari bagaimana kita mengakses informasi dengan berselancar di internet saja, tetapi perkembangan mata uang digital juga tidak terlepas dalam hal itu. Semakin populernya mata uang digital tidak di iringi dengan sistem keamanan yang handal, oleh karena itu banyak kecurangan yang terjadi sehingga banyak yang dirugikan. Salah satu contoh kecurangan yang terjadi adalah cryptojacking. Cryptojacking merugikan pengguna yang mengunjungi website tertentu yang terindikasi atau tersisipi perintah cryptojacking.

Cryptojacking adalah taktik baru dalam menambang mata uang digital secara illegal, dimana orang yang berada dibalik layar menggunakan sumber daya CPU korban sebagai proses komputasinya secara diam-diam 
tanpa sepengetahuan korban [1]. Cryptominer jenis ini tidak terlalu membahayakan secara langsung kepada para korbannya, tetapi hanya saja menggunakan akses illegal ke komputer korban dan menggunakan sumber daya korban untuk menambang crypto. Deteksi

Page|40 cryptominer jenis ini akan sulit karena efek sampingnya hanya berupa penggunaan sumber daya korban dan tidak terlalu membahayakan korban secara langsung, terutama para korban yang awam akan mengacuhkan pada saat serangan ini terjadi [2]. Malware jenis ini menyerang dengan cara korban mengakses sebuah website yang tersisipi skrip perintah malware tersebut dan malware ini menggunakan bahasa pemrograman javascript. Website saat ini tidak dipungkiri banyak menggunakan Bahasa pemrograman javascript dalam pembuatan websitenya, oleh karena itu mudah sekali menyisipkan skrip perintah dari malware ini.

Penelitian yang dilakukan oleh [3], melakukan penelitian dengan menggunakan analisis statis dan dinamis pada malware cryptojacking dengan layanan dari coinhive. Penelitian tersebut menghasilkan karakteristik kode yang unik dan dapat digunakan untuk mendeteksi kode cryptojacking dari layanan coinhive ini dengan akurasi $96 \%$, lalu merekonstruksi pengoperasian skrip cryptojacking, mempelajari kelayakan ekonomi sebagai alternatif iklan.

Penelitian [4] melakukan penelitian terhadap cryptojacking dengan survei, melakukan beberapa pengukuran untuk menetapkan prevalensi dan profitabilitasnya, menguraikan kerangka kerja etika untuk mempertimbangkan apakah itu harus diklasifikasikan sebagai serangan atau peluang bisnis.

Kurangnya pengetahuan tentang malware jenis ini mengakibatkan malware ini bisa dengan mudah menginfeksi para korban. Penyerang hanya bermodalkan skrip yang ditanam di website, dapat mendapatkan keuntungan dengan menggunakan sumber daya korban untuk melakukan cryptojacking. Cryptojacking sempat tenar pada 2017 - 2018 dan sekarang walaupun tidak sebanyak pada tahun tersebut tetapi masih banyak website menggunakan cryptojacking ini untuk mendapatkan uang selain dari iklan dan penyedia layanan semakin banyak dan beragam serta mata uang yang didapat beraneka ragam sesuai dengan yang disediakan layanan cryptojacking Penelitian ini dilakukan untuk mendapatkan informasi tentang cryptojacking baik itu pola serangannya ataupun mengatasi serangannya dengan layanan yang menyediakan cryptojacking berbeda dari penelitian sebelumnya.

\section{METODOLOGI}

Metode yang digunakan dalam penelitian ini adalah dynamic analysis dengan alur sebagai berikut:

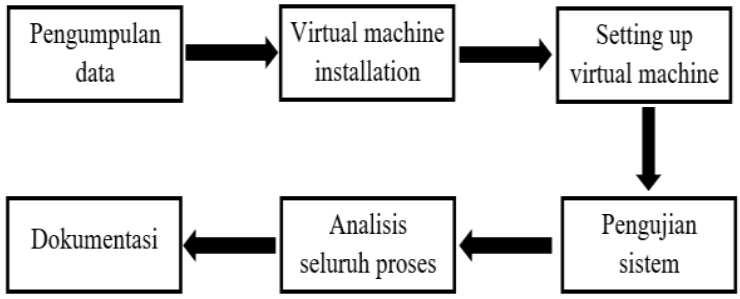

Gbr. 1.Metode penelitian

Metode dynamic analysis yaitu mencari informasi tentang malware dengan cara mengeksekusi malware dan melihat perilaku dari malware tersebut yang berjalan dalam sistem host [5]

A. Pengumpulan Data

Metode pengumpulan data menggunakan studi literature dengan mengumpulkan data dan informasi mengenai cryptojacking, termasuk berita, jurnal, dan semua informasi mengenai cryptojacking.

\section{B. Virtual machine installation}

Penelitian ini menggunakan lingkungan virtual agar aman pada saat pengujian sampel virus. Mesin virtual atau yang di kenal dengan virtual machine. Spesifikasi virtual machine yang digunakan pada penelitian adalah dapat dilihat pada Tabel I.

TABEL I

SPESIFIKASI KOMPUTER

\begin{tabular}{|c|c|c|}
\hline $\mathrm{No}$ & Uraian & Spesifikasi \\
\hline 1 & Sistem Operasi & $\begin{array}{l}\text { Windows } 10 \text { Pro 64-bit } \\
\text { (1809) }\end{array}$ \\
\hline 2 & Prosesor & $\begin{array}{l}A M D A 8-6410 \\
C P U @ \quad @ \quad 2.0 G H z \\
C P U s)\end{array}$ \\
\hline 3 & Memori & $8 G B R A M$ \\
\hline 4 & Hardisk Capasity & $500 \mathrm{~GB}$ \\
\hline
\end{tabular}

TABEL II

SPESIFIKASI VIRTUAL 1

\begin{tabular}{|c|c|l|}
\hline No & Uraian & \multicolumn{1}{|c|}{ Spesifikasi } \\
\hline 1 & Aplikasi VM & VMware \\
\hline 2 & Prosesor & Single core \\
\hline 3 & Memori & 1.5 GB \\
\hline 4 & Sistem Operasi & Windows 7 \\
\hline
\end{tabular}

TABEL III

SPESIFIKASI VIRTUAL 2

\begin{tabular}{|c|c|l|}
\hline No & Uraian & \multicolumn{1}{|c|}{ Spesifikasi } \\
\hline 1 & Aplikasi VM & VMware \\
\hline 2 & Prosesor & Single core \\
\hline 3 & Memori & 1 GB \\
\hline 4 & Sistem Operasi & Kali Linux 2019.2 \\
\hline
\end{tabular}

\section{Setting up virtual machine}

Konfigurasi virtual machine sesuai dengan kebutuhan, menginstall aplikasi untuk melakukan pengujian seperti bettercap, wireshark, dan dengan bantuan website seperti PublicWWW, minero, coinimp, dan jsecoin. Bettercap digunakan untuk sniffing dan 
melakukan javascript injection. Wireshark digunakan untuk melihat alur data yang terkirim dan melihat alur data dari penyerang sehingga dapat dijadikan sebagai digital evidence. Website publicwww digunakan untuk menampilkan website yang terdapat skrip

Page| 41 cryptojacking.

\section{Pengujian Sistem}

Pengujian system dilakukan dengan cara menjalankan malware dan dilihat bagaimana perilaku dari malware tersebut. Pengujian dilakukan dengan dua skenario, skenario pertama mencari website yang terindikasi terdapat skrip cryptojacking dan skenario kedua melakukan javascript injection.

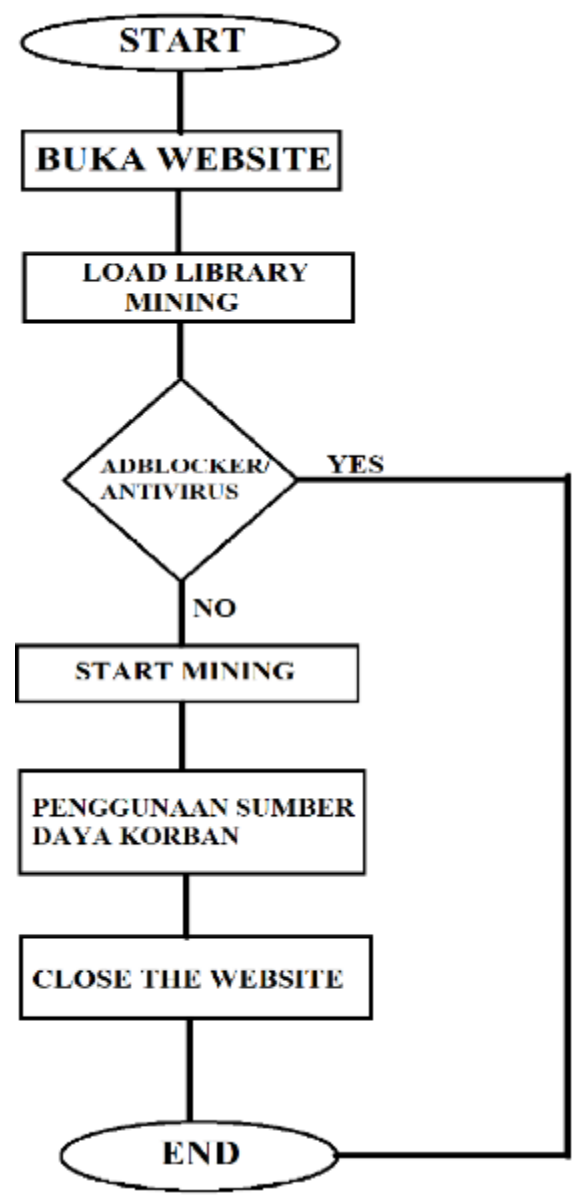

Gbr. 2.Pengujian Pertama

Flowchart pengujian skenario kedua dilakukan dengan korban membuka suatu website yang terindikasi skrip cryptojacking ini, skrip tersebut akan langsung dijalankan dan library mining akan dimuat pada halaman website tersebut, jika tidak terdapat adblocker atau antivirus maka skrip penambangan pada library mining tersebut akan berjalan dan mulai menggunakan sumber daya korban untuk menambang mata uang digital secara diam-diam tanpa disadari oleh korban. Website tersebut ditutup maka penambangan dihentikan dan selesai.

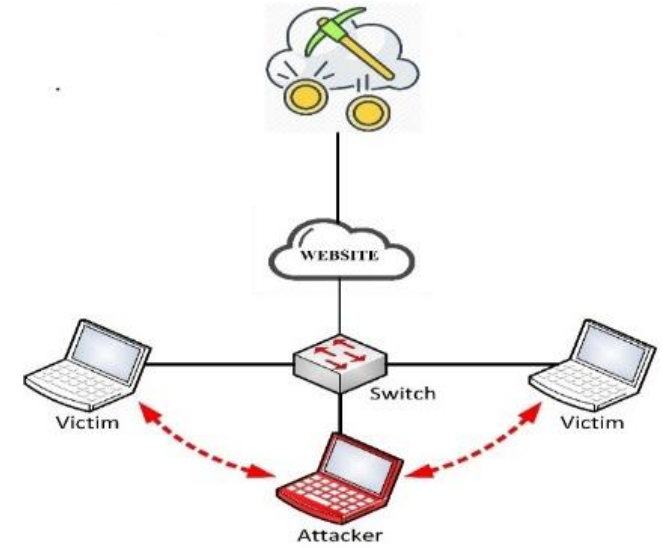

Gbr. 3.Pengujian Kedua (javascript injection)

Javascript injection disini dilakukan dengan scenario korban dan pelaku cryptojacking berada dalam jaringan yang sama yaitu wifi, dimana pelaku melakukan javascript injection kepada korban dengan bantuan aplikasi bettercap untuk menyisipkan perintah cryptojacking pada korban.

\section{E. Analisis seluruh proses}

Analisis dilakukan dengan cara melihat bagaimana perilaku malware setelah dijalankan, dari situ didapatkan pengetahuan bagaimana malware tersebut menyerah, melihat dampaknya, dan didapatkan solusi untuk mengatasinya.

\section{F. Dokumentasi}

Hasil dari analisis malware tersebut di dokumentasikan sebagai bukti dari analisis tersebut, sehingga tidak disangka mengada-ada atau mengarang

\section{HASIL DAN PEMBAHASAN}

Hasil dan pembahasan, tujuannya adalah untuk mendapatkan jawaban atas permasalahan dari tema yang diangkat didalam penelitian. Proses analisis ini disusun secara terstruktur untuk mendapatkan skema investigasi ada performa pc yang mengakses website yang telah disisipi perintah cryptojacking. 


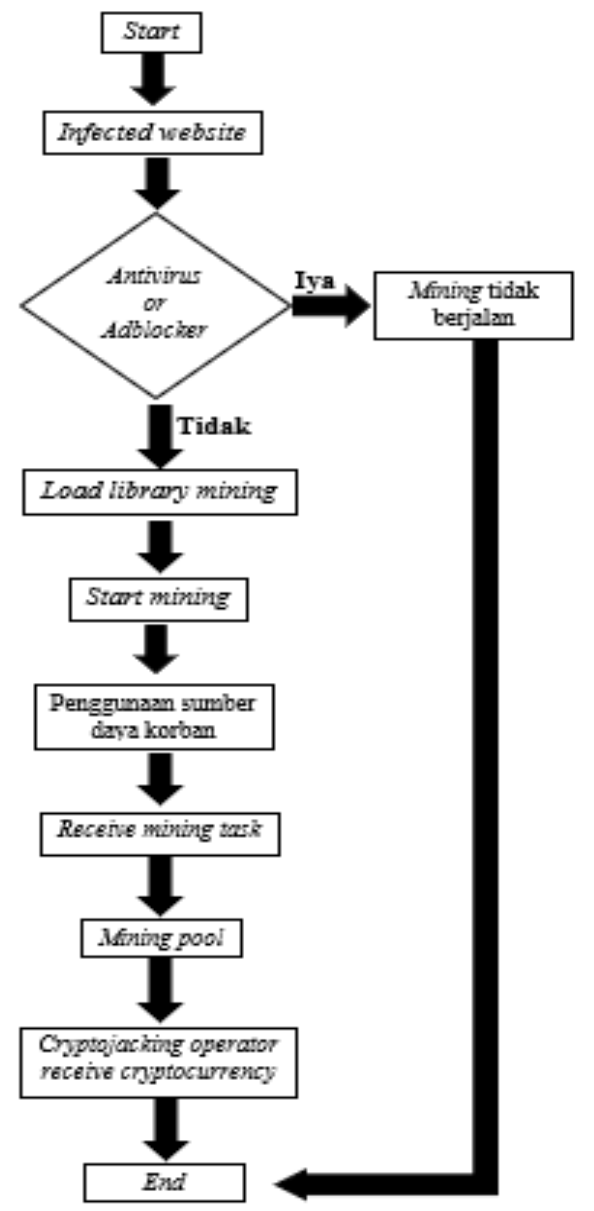

Gbr. 4.Flowchart serangan Cryptojacking

Flowchart serangan cryptojacking ini adalah pola serangan cryptojacking, dimana cryptojacking menginfeksi suatu website baik itu ditanam langsung ke website atau dengan javascript injection yang bersifat local pada jaringan tertentu. Website yang telah terinfeksi dari skrip cryptojacking maka jika ada yang mengakes website tersebut maka penambangan akan berjalan kecuali jika terdapat antivirus atau adblocker pada perangkat. Mining berjalan dan akan menggunakan sumber daya korban yang mengakses. Cryptojacking operator akan menerima mata uang digital dengan hanya menunggu dan skrip mining tersebut akan berjalan terus menerus selama ada yang mengakses website yang terinfeksi tersebut.

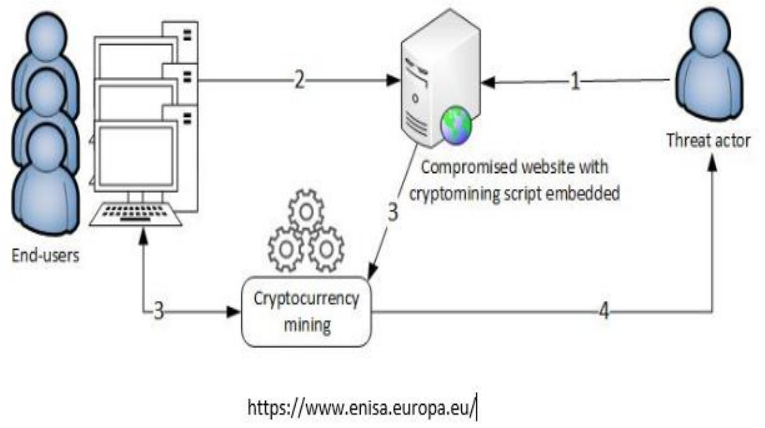

Gbr. 5.Alur serangan Cryptojacking
Gambar 5 adalah alur cryptojacking dimana pertama pelaku menanamkan skrip cryptojacking pada website. End users atau pengguna mengakses website tersebut dan skrip cryptojacking berjalan. Sifat cryptojacking berjalan dilatar belakang tanpa ada pemberitahuan maka pengguna tidak mengetahui bahwa didalam website tersebut terdapat skrip cryptojacking dan berjalan untuk menambang mata uang digital demi kepentingan pelaku. Pelaku mendapatkan uang digital dari hasil penggunaan sumber daya pengguna begitu banyak.

Praktik cryptojacking berbasis browser telah berkembang sangat pesar dengan beberapa kasus yang sudah terungkap. Pelaku cryptojacking tidak hanya menginfeksi didalam website tetapi pada iklan yang termuat dalam website dapat dengan mudah disisipi oleh kode cryptojacking. Kode javascript yang dijalankan secara otomatis pada saat korban membuka website tersebut. Skrip Cryptojacking tidak merusak komputer atau data korban, melainkan hanya mencuri sumber daya pemrosesan CPU

\begin{tabular}{|c|c|c|c|c|}
\hline Tine & Souce & Destration & Protocel & lerght Into \\
\hline 99821.381237 & 192.168 .244 .129 & 45.79.81.15 & TCP & $6649370+443$ [SMI] Sen=8 Vin=8192 Len=8 115S=1460 IIS=2: \\
\hline 99921.381603 & 192.168 .244 .129 & 45.79.81.15 & $T C P$ & $6649371+443[5 \mathrm{SMI}] \mathrm{Seg}=8 \mathrm{Vin}=8192$ Len=8 15S=1458 IIS=2. \\
\hline 108324,308870 & 192.168.24.129 & 45.79.81.15 & $T C P$ & 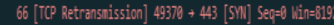 \\
\hline 198424,387027 & 192.168 .244 .129 & 45.79.81.15 & $T C P$ & 66 [TeP Retransnission] $49371+43[$ [SW] Seq=0 kin=819. \\
\hline 108824.552530 & 192.168 .244 .129 & 45.79 .81 .15 & $T C P$ & $5449371+443[$ [ACX] Seg=1 Ack=1 lin=64249 Len=8 \\
\hline 198924,553273 & $192,168.244,129$ & 45.79.81.15 & TLSM. 2 & 232 Client Hello \\
\hline 199224,558338 & 192.168 .244 .129 & 45.79.81.15 & $T C P$ & $5449370+433[A C X]$ Seg=1 Ack=1 Lin=64249 Len=8 \\
\hline 109324.560433 & 192.168.244.129 & 45.79.81.15 & TLSS .2 & 232 Client Hello \\
\hline 112026.392249 & 192.168 .244 .129 & 45.79.81.15 & TCP & $5449371+433$ [ACC] Seq=179 Ack=1491 lin=22840 Len=8 \\
\hline 112226.395120 & 192.168.244.129 & 45.79.81.15 & TCP & $5449371+43[$ [ACC] Seg=1799 Ack=2801 lin=644240 Len=8 \\
\hline 112426.395312 & 192.168 .244 .129 & 45.79.81.15 & $T C P$ & $5449371+443[\mathrm{ACC}] \mathrm{Seg}=179 \mathrm{Ack}=3000$ Vinn=64441 Len=8 \\
\hline 112526.422574 & 192.168 .244 .129 & 45.79.81.15 & TLSH.2 & 236 Client Key Exchange, Change Cipher Spec, Encrypted Hi \\
\hline 112826.424901 & 192.168.244.129 & 45.79.81.15 & $T C P$ & $5449370+433[A C C]$ Seg=179 Ack=1491 Vin=62840 Len=8 \\
\hline 113026.425775 & 192.168 .244 .129 & 45.79.81.15 & $T C P$ & $5449370+443[\mathrm{ACC}] \mathrm{Seg}=179$ Ack=2801 line=64240 Len=8 \\
\hline 113226.425916 & 192.168 .244 .129 & 45.79.81.15 & TCP & $5449370+443[$ [ACC] Seqa179 ACk=3080 linn=64441 Len=8 \\
\hline 113326.442255 & $192.168 .244,129$ & 45.79.81.15 & TLSH.2 2 & 236 Client Key Exchange, Change Cipher Spec, Encrypted H. \\
\hline 113626.707965 & 192.168 .244 .129 & 45.79.81.15 & TCP & $5449371+43[$ [ACC] Seq3361 Ack=3107 Vin=63934 Len=0 \\
\hline 113826.754346 & 192.168 .244 .129 & & $T C P$ & 361 ACk=3107 lin=639934 Len=0 \\
\hline
\end{tabular}

Wireshark digunakan untuk menganalisa jaringan untuk melihat alur dari dan kemana data dikirimkan pada saat jaringan terkoneksi internet dan mengakses website. Hasil dari penggunaan wireshark dapat dilihat, pada saat mengakses website yang terjangkit skrip cryptojacking, komputer tidak hanya mengirim data pada website yang dituju tetapi juga website layanan cryptojacking seperti diatas dengan ip 45.79.81.15 yaitu ip website minero.cc karena website tersebut memakai layanan dari minero untuk menambang mata uang digital. TCP adalah suatu protocol pengiriman data yang bersifat connection oriented dan berbasis IP (Internet Protocol). Fungsi dari OSI layer TCP yang berada pada layer transport adalah mengatur pengiriman suatu data dari client ke server, yang berarti client mengirim data kepada ip 45.79.81.15 yang tidak lain website layanan dari minero sebagai server yang menerima data.

Pengujian kedua melakukan javascript injection, disini dilakukan dengan scenario korban dan pelaku cryptojacking berada dalam jaringan yang sama yaitu wifi, dimana pelaku melakukan javascript injection 
kepada korban dengan bantuan aplikasi bettercap untuk menyisipkan perintah cryptojacking pada korban.

Serangan terjadi pada saat korban dan pelaku berada dalam satu wifi yang sama, dengan menggunakan aplikasi bettercap pelaku dapat melakukan javascript Page 43 injection pada korban.

Bettercap selain dapat melakukan javascript injection, dapat juga melakukan sniffing sehingga dapat terlihat ip address yang tersambung pada wifi tersebut.

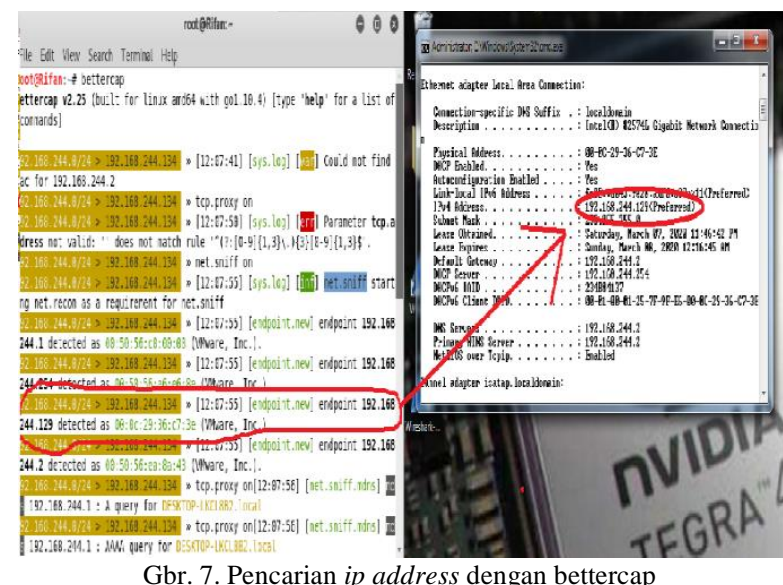

Pencarian ip address yang terhubung pada wifi menggunakan aplikasi bettercap. Pencarian ip address dilakukan pelaku untuk melakukan sniffing sehingga pelaku dapat leluasa memilih korban untuk eksekusi javascript injection pada jaringan wifi tersebut.

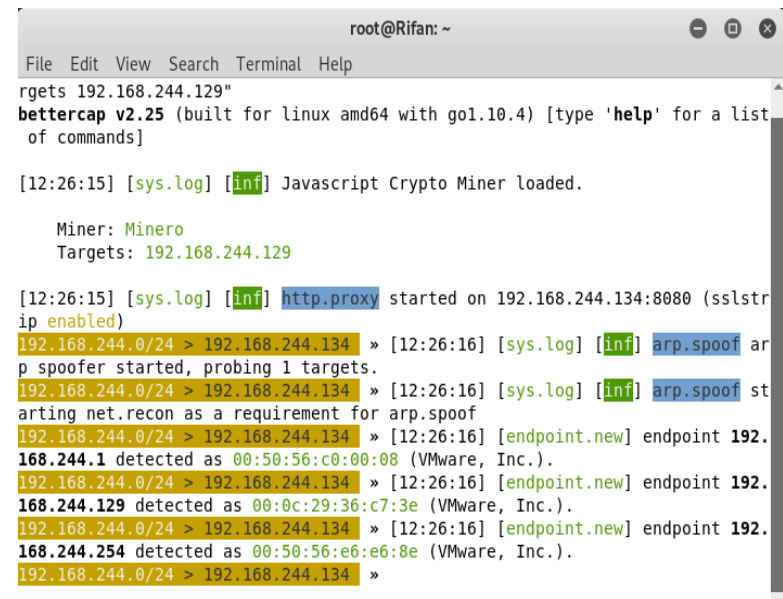

Gbr. 8. Javascript injection dengan bettercap

Javascript injection dilakukan dengan menginjeksi skrip cryptojacking kepada korban pada jaringan wifi yang sama. Korban pada saat terkena serangan javascript injection ini pada saat mengakses website apapun selama itu protocol http maka skrip cryptojacking akan dijalankan.

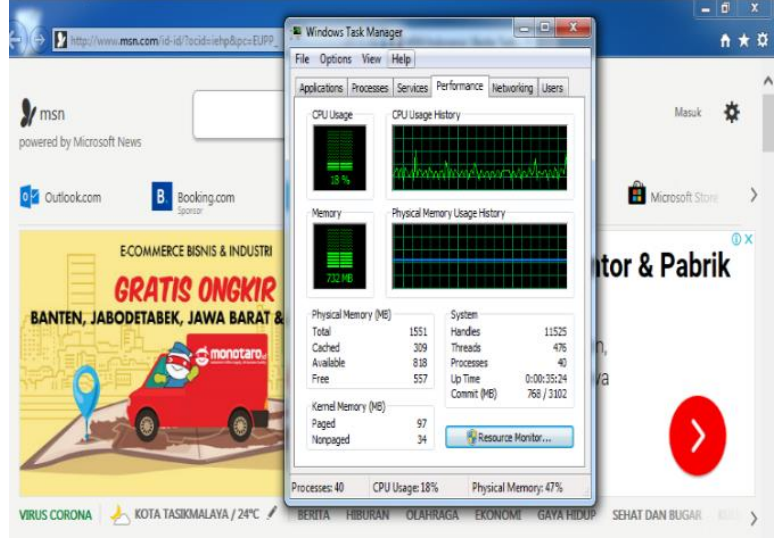

Gbr. 9. Sebelum terkena javascript injection

Gambar 9 adalah pada saat korban mengakses website sebelum terkena javascript injection dengan rata-rata pemakaian cpu hanya berkisar $17-20 \%$.

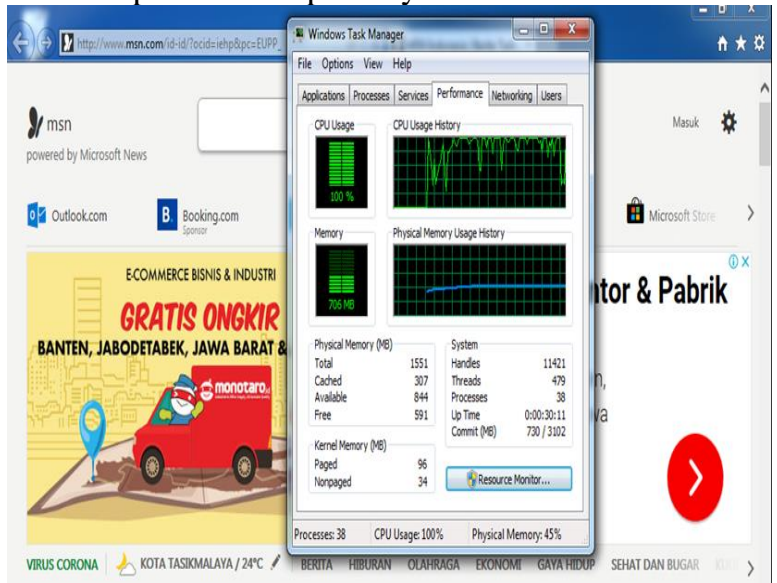

Gbr. 10. Setelah terkena javascript injection

Gambar 10 adalah ketika korban mengakses website yang sama seperti sebelumnya tetapi telah dilakukan javascript injection pada korban. Dampaknya penggunaan cpu korban dengan rata-rata $95-100 \%$, sangat tinggi penggunaan cpu yang hanya membuka satu website saja.

\section{A. Layanan Cryptojacking (coinimp, jsecoin dan minero}

Coinimp adalah layanan penambangan dengan javascript yang mudah digunakan. Coinimp di rilis pada tahun 2017 dengan tujuan memberikan solusi penambangan yang menguntungkan bagi pengguna. Semenjak layanan ini dibuat sampai sekarang banyak pengguna yang memakai layanan ini dan layanan ini bisa dianggap layanan penambangan javascript yang popular dan dapat diandalkan.

JSEcoin adalah layanan penambangan dengan javascript, sama halnya dengan coinimp. Javascript penambangan ini sebenernya alternatif untuk mendapatkan uang selain iklan yang disematkan dalam website. Javascript yang digunakan layanan ini dimuat sebagai proses async post-page-load sehingga tidak akan mengganggu kinerja situs website dan pengalaman pengguna pada saat mengakses sebuah 
website. Layanan ini bersifat transparan pada saat penambangan, layanan ini akan memberi tahu tahu pengguna bahwa penambangan javascript sedang berjalan dalam bentuk notifikasi di bagian bawah halaman website dan pengguna harus memberikan persetujuan sebelum penambangan dimulai.

Minero adalah layanan penambangan mata uang digital dengan javascript pada sebuah website, tidak berbeda jauh dengan coinimp dan jsecoin. Layanan ini bersifat tersembunyi berbeda dengan layanan jsecoin yang transparan, layanan ini akan menggunakan cpu korban dengan sembunyi untuk menambang mata uang digital tanpa harus persetujuan dari pengguna

Mata uang digital yang dipakai masing-masing layanan berbeda, coinimp dengan mata uang digital websitecoin (website) nilai pertukarannya untuk 1 websitecoin dihargai senilai dengan \$0.001489 USD. Layanan jsecoin mempunyai mata uang digital sendiri yang sama dengan nama websitenya yaitu jsecoin (jse) dimana nilai pertukarannya untuk 1 jsecoin senilai dengan \$0.000167 USD. Layanan penambangan javascript ini sebelumnya menggunakan mata uang monero (xmr) dimana nilai tukarnya untuk 1 monero senilai dengan \$64.78 USD, tetapi pada tanggal 30 november 2019 terdapat perubahan algoritma sehingga tidak dapat berjalan pada penambangan javascript. Perubahan algoritma dari monero tidak berdampak pada layanan minero, dimana minero tetap menggunakan mata uang digital ini tanpa kesulitan.

Layanan penambangan javascript atau cryptojacking ini terdapat perbedaan yang begitu terlihat selain dari mata uangnya yaitu tranparansi layanannya dimana layanan dari coinimp dan minero berjalan dilatar belakang pengguna tanpa pengguna mengetahuinya, pengguna mau tidak mau harus menjalankan penambangan javascript ini pada website yang di akses. Layanan jsecoin berbeda, layanan ini akan menampilkan pemberitahuan yang ditampilkan pada bagian bawah halaman website dan pengguna harus memberikan persetujuan sebelum penambangan dimulai.

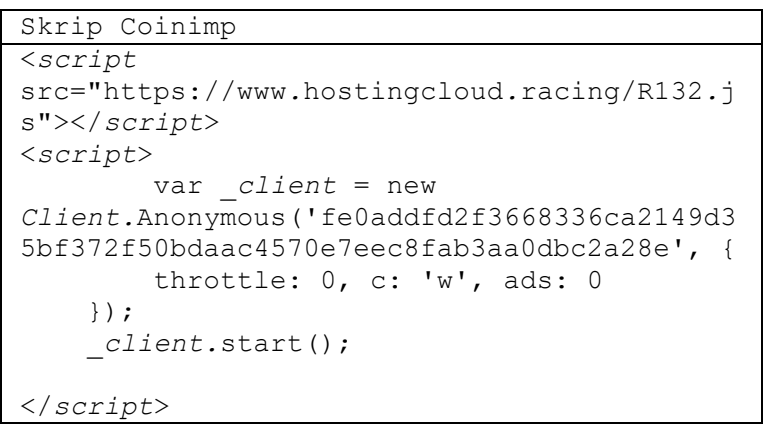

HTML <script $>$ element digunakan untuk menulis skrip atau lebih tepatnya adalah untuk menyisipkan skrip seperti javascript pada sisi client, baik itu ditulis secara langsung didalam element $\langle$ script $\rangle$, maupun merujuk sumber file eksternal dengan attribute src. Attribute src berfungsi untuk menentukan link (URL) yang merujuk pada sumber file script external. File eksternal yang digunakan terdapat pada website hostigcloud dengan nama file nya R132.js . Skrip diatas juga memuat fungsi throttle yaitu teknik dimana tidak peduli berapa kali pengguna menyalakannya maka fungsi hanya sekali dalam interval waktu tertentu.

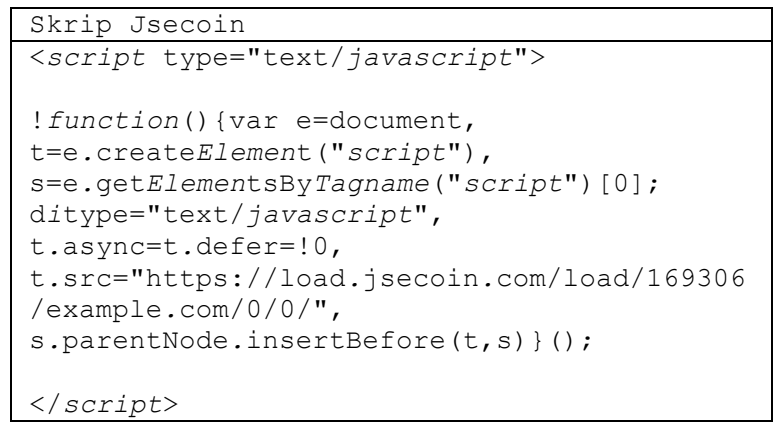

Skrip ini diawali dengan tag $<$ script type="text/javascript" $>$ dan di akhiri dengan $</$ script $>$ atribut yang menginformasikan kepada browser bahwa program script yang ada dalam tag tersebut adalah javascript dalam format text. Fungsi atau function didalam javascript adalah sebuah objek, karena memiliki property dan juga method. Fungsi document di deklarasikan menjadi variable $e$, dan "e.createElement ("script")" membuat elemen html yang ditentukan oleh tagname dimana tagname untuk skrip diatas bernama "script". Tagname adalah sebuah string yang menentukan tipe dari elemen yang akan dibuat, ketika dipanggil pada sebuah dokumen HTML, "createElement()" mengubah tagname menjadi lower case sebelum membuat elemen. Skrip "s=e.getElementsByTagname ("script")" berfungsi untuk memilih elemen-elemen dengan tag HTML tertentu.

"t.async=t. defer $=! 0, t . s r c=" h t t p s: / /$

Skrip

load.jsecoin.com/load/169306/example.com/0/0/

"', fungsi dari async digunakan untuk menunjukan ke browser bahwa file skrip dapat di eksekusi secara asinkron, skrip menjadi siap setelah diambil bersamaan dengan pasing dokumen. Fungsi dari defer akan mengunduh file selama parsing html dan hanya akan menjalankannya setelah parsing selesai. Skrip diatas berfungsi untuk memanggil atau mengeksekusi file eksternal dari website load.jsecoin.com.

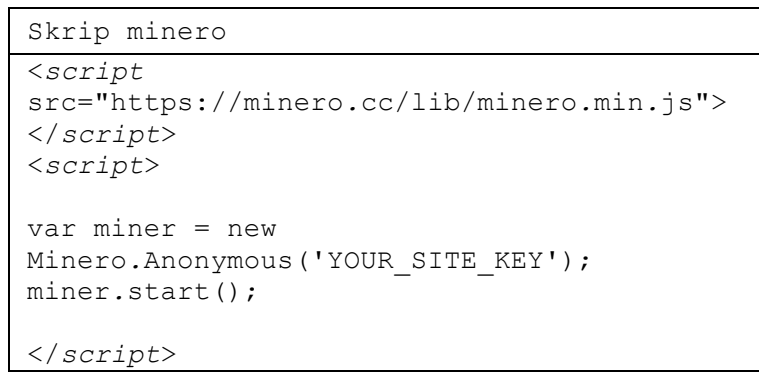

Skrip "script src="https://minero.cc/lib/ minero.min.js"" digunakan memuat library untuk 
digunakan di website. Skrip "var miner = new Minero.Anonymous ('YOUR SITE KEY');

miner.start ();" pembuatan fungsi miner untuk digunakan sebagai deklarasi skrip penambangan dengan parameter kunci website yang telah ditentukan oleh website layanan minero.

\section{B. Pemakaian $C P U$}

Analisis dampak cryptojacking dilihat dari aspek pemakaian CPU dari beberapa sampel website yang ditentukan. Analisis dilakukan dengan cara melihat pemakaian CPU dari hasil membuka sampel website yang ditentukan baik itu javascriptnya di aktifkan, javascript di matikan, dan memakai ekstensi browser seperti adblock.
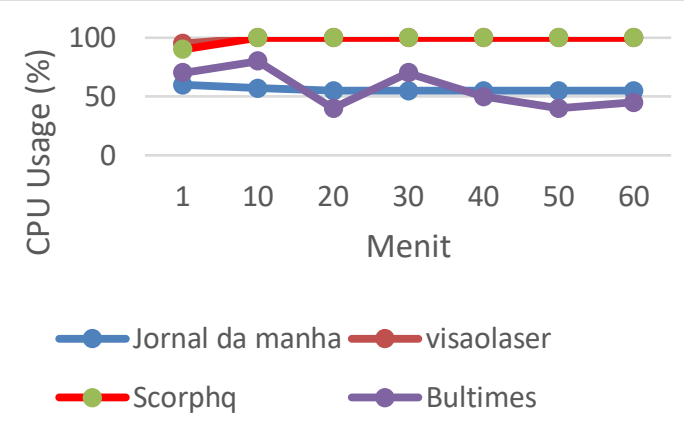

Gbr. 11 Pemakaian CPU (javascript enable)

Pemakaian CPU dari website yang terindikasi skrip penambangan. Website scorphq mengatur $100 \%$ pemakaian cpu pengunjung pada saat mengunjungi website tersebut, penggunaan cpu pengunjung paling tinggi. Website bultimes diatur untuk menggunakan cpu pengunjung dengan rata-rata sebesar 50\% agar bisa menambang mata uang digital, lebih sedikit dibanding dengan sampel yang lain. Sampel ketiga yaitu website journal da manha diatur agar cpu pengujung untuk menambang dengan rata-rata sebesar $55 \%$ dari total keseluruhan dari cpu pengunjung lebih tinggi dibanding sampel sebelumnya. Sampel terakhir yaitu website visaolaser dimana diatur sebesar $100 \%$ pemakaian cpu pengunjung untuk digunakan menambang mata uang digital. Semakin tinggi penggunaan cpu korban semakin banyak pula uang digital yang didapat.

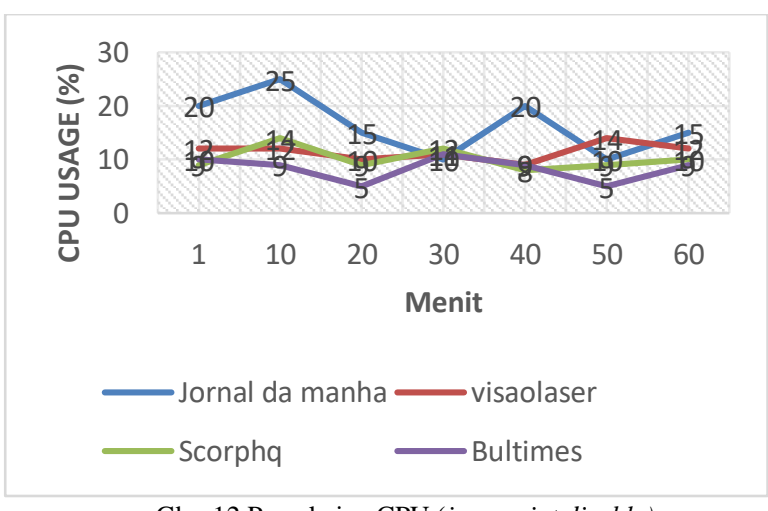

Gbr. 12 Pemakaian CPU (javascript disable)
Pemakaian CPU ini berbeda jauh hasilnya dari sebelumnya yang javascriptnya diaktifkan. Javascript tidak diaktifkan pada browser maka otomatis skrip cryptojacking tidak akan berjalan karena skrip cryptojacking Bahasa pemrogramannya javascript. Website jornal da manhha yang jika javascriptnya diaktifkan memakai cpu sebesar 55\% tetapi jika javascriptnya dimatikan hanya rata-rata memakai $15 \%$ cpu pengunjung website tersebut. Website visaolaser yang sebelumnya memakai $100 \%$ sekarang jika javascriptnya dimatikan menjadi rata-rata $12 \% \mathrm{cpu}$ pengunjung website. Website scorphq jika diaktifkan javascript memakai cpu pengunjung website sebesar $100 \%$ maka sekarang javascript dimatikan menjadi rata-rata sebesar $10 \%$ cpu yang terpakai oleh pengunjung website tersebut. Website bultimes jika javascript aktif maka akan memakai cpu pengunjung sebesar 50\% tetapi jika javascript tidak diaktifkan maka hanya akan memakai cpu pengunjung rata-rata sebesar $9 \%$.

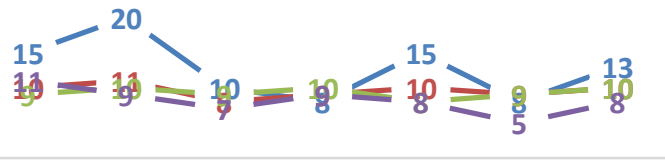

$$
\begin{aligned}
& \begin{array}{lllllll}
1 & 10 & 20 & 30 & 40 & 50 & 60
\end{array} \\
& \text { - Jornal da manha - - visaolaser } \\
& \text { - - Scorphq } \quad-\text { - Bultimes }
\end{aligned}
$$

Gbr. 13 Pemakaian CPU (ekstensi adblocker)

Penggunaan ekstensi di browser seperti adblocker hasilnya tidak berbeda jauh dengan hasil jika javascript dinonaktifkan tetapi hasilnya sedikit lebih rendah karena iklan yang dimuat didalam websitenya tidak ditampilkan

\section{Pemakaian sumber daya baterai}

Analisis dilakukan dengan cara membuka website sampel dari kedua layanan tersebut dan dilihat dampak pemakaian baterainya dalam waktu 60 menit. Hasilnya dalam bentuk grafik sehingga dapat mudah dibaca.

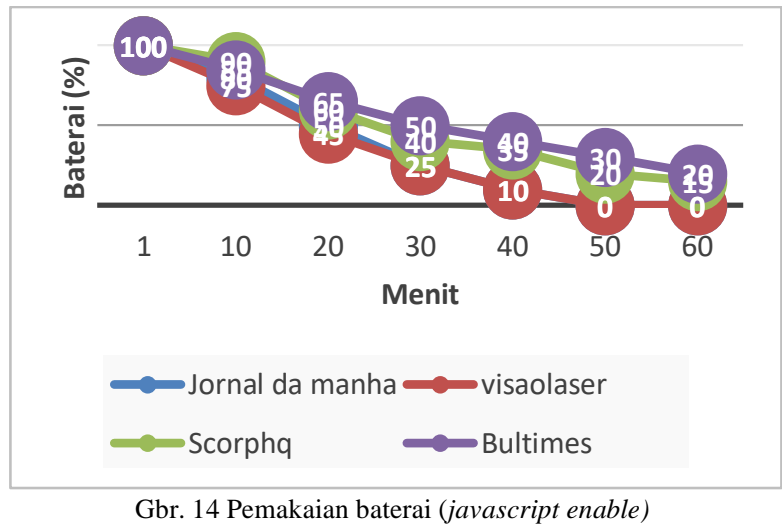


Dampak dari penggunaan javascript penambangan dapat dilihat dari pemakaian baterai, biasanya penambangan javascript yang terdapat pada website akan menggunakan banyak sumber daya seperti pemakaian baterai. Penggunaan cpu oleh javascript penambangan berdampak pada baterai yang digunakan, semakin tinggi penggunaan cpu maka akan semakin berkurang daya baterainya dengan waktu yang cepat. Website visaolaser dan scorphq penggunaan cpunya sangat tinggi berdampak pada baterai berkurang dengan cepat, hanya dengan membuka website ini selama $40-50$ menit baterai terkuras habis. Website jornal da manha dan bultimes memakai cukup banyak cpu walaupun tidak sebanyak website visaolaser dan scorphq tetapi tetap saja menguras sumber daya baterai cukup banyak dengan selama 60 menit membuka salah satu dari kedua website ini akan tersisa hanya sedikit sekitar $15-20 \%$ saja.

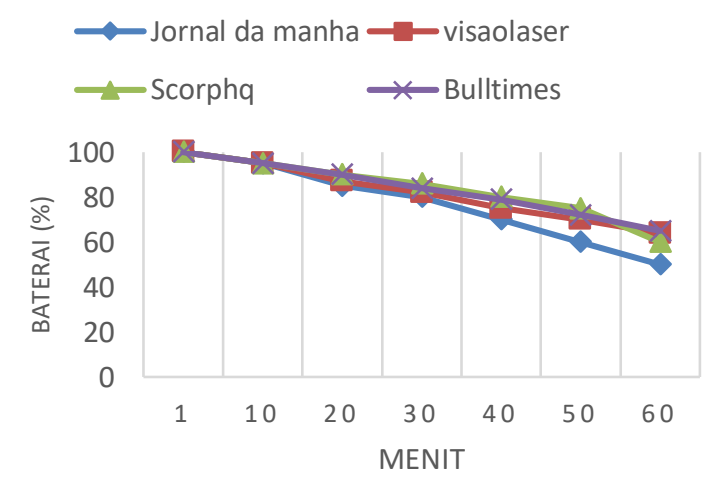

Gbr. 15 Pemakaian CPU (javascript disable)

Hasil dari javascript dinonaktifkan untuk sampel website yang terindikasi penggunaan javascript penambangan berbeda jauh dengan jika javascriptnya diaktifkan. Javascript tidak diaktifkan sehingga cryptojacking tidak bekerja karena cryptojacking menggunakan skrip dalam bentuk javascript, oleh karena itu penggunaan sumber daya baterai tidak terlalu banyak. Sisa baterai tidak banyak berkurang karena hanya menampilkan tampilan website tanpa mengaktifkan perintah cryptojacking.

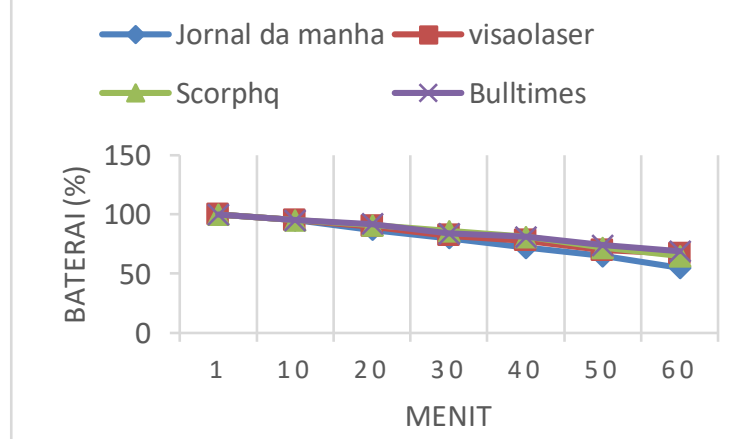

Gbr. 16 Pemakaian baterai (ekstensi adblocker)
Pemakaian baterai pada saat menggunakan ekstensi adblock tidak berbeda jauh dengan tidak mengaktifkan javascript. Perbedaannya hanya sedikit lebih banyak sisa baterai pada saat mengatifkan ekstensi adblock karena adblock tidak menjalankan perintah cryptojacking tetapi iklan yang terdapat pada website tidak ditampilkan sehingga mengurangi pemakaian sumber daya beterai.

\section{Pemakaian bandwidth}

Analisis dampak dari cryptojacking dilihat dari pemakaian bandwidth, analisis dilakukan dengan membuka website yang terjangkit skrip cryptojacking selama 30 menit dan dilihat pemakaian bandwidth

TABEL IV

PEMAKAIAN BANDWIDTH

\begin{tabular}{|c|c|c|c|c|}
\hline \multirow{2}{*}{$\begin{array}{c}\text { Size } \\
\text { Menit }\end{array}$} & $\begin{array}{c}\text { Jornal } \\
\text { da } \\
\text { manh } \\
\mathrm{a}\end{array}$ & Scorphq & $\begin{array}{c}\text { Visaolas } \\
\text { er }\end{array}$ & $\begin{array}{c}\text { Bultime } \\
\text { s }\end{array}$ \\
\cline { 2 - 5 } & $\begin{array}{c}6.5 \\
\mathrm{MB}\end{array}$ & $1.1 \mathrm{MB}$ & $2.2 \mathrm{MB}$ & $0.5 \mathrm{MB}$ \\
\hline 10 & $\begin{array}{c}15 \\
\mathrm{MB}\end{array}$ & $30 \mathrm{MB}$ & $40 \mathrm{MB}$ & $10 \mathrm{MB}$ \\
\hline 20 & $\begin{array}{c}20 \\
\mathrm{MB}\end{array}$ & $60 \mathrm{MB}$ & $75 \mathrm{MB}$ & $20 \mathrm{MB}$ \\
\hline 30 & $\begin{array}{c}30 \\
\mathrm{MB}\end{array}$ & $80 \mathrm{MB}$ & $90 \mathrm{MB}$ & $30 \mathrm{MB}$ \\
\hline
\end{tabular}

Pengaturan yang dilakukan pada saat melakukan cryptojacking berpengaruh terhadap pemakaian bandwidth korban. Semakin tinggi pengaturan yang dilakukan maka semakin tinggi pula bandwidth terpakai, seperti scorphq yang setting 100\% untuk cryptojacking maka akan semakin tinggi pemakaian bandwidth, website ini memakai $80 \mathrm{MB}$ data korban selama 30 menit saat membuka website tersebut. Kecepatan internet berpengaruh juga pada saat pemakaian kuota korban, semakin cepat maka semakin banyak pula kuota korban terkuras.

\section{E. Digital evidence (javascript injection)}

Digital evidence yang dimaksud adalah barang bukti atas dilakukannya javascipt injection yang telah terjadi pada komputer korban.

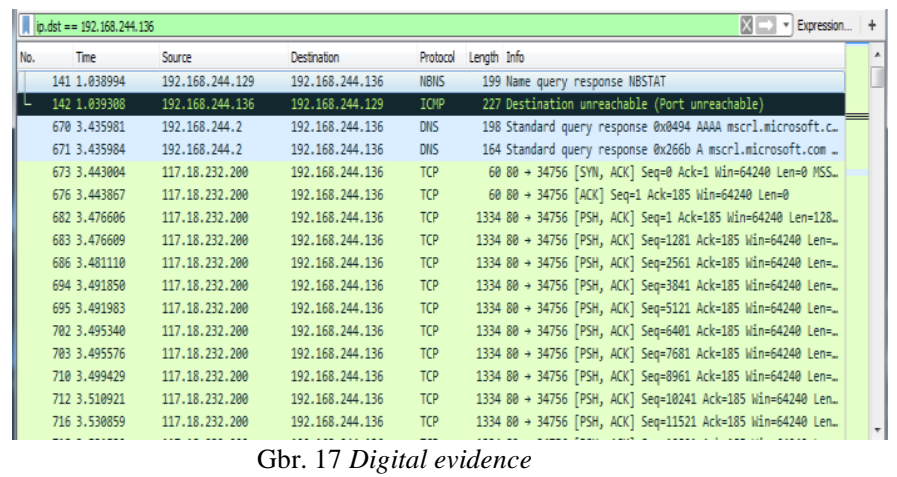


Page | 47 sama seperti pada korban.

\section{F. Deteksi serangan cryptojacking}

Deteksi cryptojacking dapat dilakukan dengan cara melihat tanda-tanda dari sumber daya pada laptop atau komputer pada saat mengakses website, seperti kinerja lambat, sistem overheating, baterai menjadi cepat habis itu pertanda bahwa sumber daya disalah gunakan untuk menambang mata uang digital atau cryptojacking oleh pihak lain. Mengikuti perkembangan tren cryptojacking solusi lain untuk mendeteksi cryptojacking. Informasi tentang pengiriman dan kode cryptojacking, memahami perangkat lunak dan perilaku dapat juga membantu untuk mendeteksi cryptojacking ini.

\section{G. Mengurangi serangan cryptojacking}

Mengurangi cryptojacking ini dapat dilakukan dengan memblokir atau menutup website yang terindikasi menjalankan skrip penambangan. Memahami cryptojacking dapat berasal dari mana saja, melihat dan menghindari membuka url atau iklan-iklan yang tidak jelas dan mencurigakan. Memasang pemblokiran iklan pada browser, penyebaran skrip cryptojacking sering dikirimkan melalui iklan website dengan memasang pemblokiran iklan dapat menjadi cara efektif untuk menghentikan serangan cryptojacking. Perlindungan endpoint yang mampu mendeteksi skrip penambangan crypto, banyak antivirus telah menambahkan deteksi penambangan crypto pada produk mereka.

\section{KESIMPULAN DAN SARAN}

Berdasarkan hasil penelitian yang telah dilakukan dapat diambil kesimpulan sebagai berikut:

1. Cryptojacking menyerang dengan cara korban mengakses sebuah website yang tersisipi skrip perintah malware tersebut dan malware ini menggunakan bahasa pemrograman javascript.

2. Penyerang hanya bermodalkan skrip yang ditanam di website, dapat mendapatkan keuntungan dengan menggunakan sumber daya korban untuk melakukan cryptojacking.

3. Dampak yang disebabkan oleh cryptojacking tidak langsung merusak ke komputer korban tetapi hanya menggunakan sumber daya korban untuk menambang mata uang digital, sehingga menguras cukup banyak sumber daya baterai.

Adapun saran yang dapat dikemukakan agar untuk kedepannya menjadi perbaikan dan pertimbangan adalah sebagai berikut:

1. Sebaiknya penelitian selanjutnya diharapkan untuk mengkaji lebih banyak sumber maupun referensi yang terkait dengan crytojacking agar hasil penelitiannya dapat lebih lengkap dan lebih baik lagi

2. Diharapkan juga memberikan solusi dalam bentuk aplikasi sehingga dapat lebih bermanfaat bagi banyak orang.

\section{DAFTAR PUSTAKA}

[1] M. Musch, C. Wressnegger, M. Johns and K. Rieck, "Webbased Cryptojacking in the Wild," 2018.

[2] G. Hong, Z. Yang, S. Yang, L. Zhang, Y. Nan, Z. Zhang, M. Yang, Y. Zhang, Z. Qian and H. Duan, "How You Get Shot in the Back: A Systematical Study about Cryptojacking in the Real World," 2018.

[3] M. Saad, A. Khormali and A. Mohaisen, "End-to-End Analysis of In-Browser Cryptojacking," 2018.

[4] S. Eskandari, A. Leoutsarakos, T. Mursch and J. Clark, "A first look at browser-based cryptojacking," 2018.

[5] U. Dolly, V. Mehra and V. Vinod, "Basic survey on Malware Analysis Tools and Techniques," International Journal on Computational Sciences \& Applications (IJCSA), 2014.

[6] C. Curtsinger, B. Livshits, B. Zorn and C. Seifert, "ZOZZLE: Fast and Precise In-Browser JavaScript Malware Detection," 2011.

[7] A. Zimba, Z. Wang and M. Mulenga, "Cryptojacking injection: A paradigm shift to cryptocurrency-based webcentric internet attacks," 2019.

[8] D. Septiana, N. Widiyasono and H. Mubarok, "Investigasi Serangan Malware Njrat Pada PC," Jurnal Edukasi dan Penelitian Informatika (JEPIN), 2016.

[9] T. P. Setia, N. Widiyasono and A. P. Aldya, "Analysis Malware Flawed Ammyy RAT Dengan Metode Reverse Engineering," Jurnal Informatika: Jurnal Pengembangan IT (JPIT), vol. III, pp. 1-9, 2018.

[10] J. Bonneau, A. Miller, J. Clark, A. Narayanan, J. A. Kroll and E. W. Felten, "SoK: Research Perspectives and Challenges for Bitcoin and Cryptocurrencies," 2015.

[11] Z. Cheng, T. Schmidt, G. Liu and R. Domer, "Thread- and Data-Level Parallel Simulation in SystemC, a Bitcoin Miner Case Study," 2018. 